Background: Breast cancer is still a great cause of concern in oncology, with high prevalence. Besides mammography, ultrasonography, and magnetic resonance imaging, elastography is an imaging technique recently developed and offers new breast imaging possibilities, mapping breast elasticity. The aim of our study was to evaluate the morphology of cystic breast lesions with special attention to quantification of Young moduli distribution and possible modification of the morphological elastographic score in breast lesions. Material and methods: Eighteen breast cystic lesions were evaluated in patients aged 26-55 (36.6 \pm 8.8 ) with sonography, shear wave elastography and fine needle biopsy.

Results: All lesions were diagnosed as benign cysts. The difference between glandular tissue stiffness and cystic lesion residual stiffness was not statistically significant $(p=0.64)$. But comparing the cystic lesion with the area under the cyst and margin, the difference was statistically significant ( $p<0.001$ and $p=0.025$ respectively). The differences in stiffness heterogeneity between cyst and glandular tissue, margin and area under the cyst were significant $(p<0.001 ; p=0.014$; $p=0.017$ respectively). The mean percentage of area within the lesion with detectable shear wave propagation was $61.6 \%(10-100 \%)$. The percentage of detectable propagation within the lesion negatively correlated with lesion volume (Rs $=-0.65, p=0.003)$. Also lesion elastographic heterogeneity correlated negatively with cyst volume ( $\mathrm{Rs}=-0.53$, $p=0.02$ ).

Conclusions: Shear wave elastography predicts breast cysts with characteristic morphology. Further research to compare it with malignant lesions is needed.

Key words: elastography, ultrasonography, breast lesion, breast cyst, breast cancer, screening.

\section{Morphological analysis of breast cystic lesions in shear wave elastography}

\author{
Paweł Rzymski, Tomasz Opala
}

Department of Mother's and Child's Health, Poznan University of Medical Sciences, Gynaecological and Obstetrical University Hospital, Poznan

\section{Introduction}

Breast cancer is still a great cause of concern in oncology, with high prevalence. There are non-invasive methods evaluated as screening tools for breast cancer. Among them mammography remains the gold standard worldwide in several strata of the population. In abnormal results further diagnostics are needed, such as non-invasive ultrasound or magnetic resonance imaging as well as invasive fine needle or core biopsy and surgery. Mammography has sufficient detecting power, but in populations with smaller and dense breasts leads to an excessive false positive rate. Ultrasound as an additional method reduces the false positive rate, but still the diagnostic process is aggressive, with $10-30 \%$ of biopsies in malignant lesions and $70-90 \%$ in benign. It results in patients' stress and higher costs [1-3].

In recent years new diagnostic tools have been evaluated. Elastic properties of human tissues raised interest for medical applications. Elastography is an imaging technique developed over the last 20 years and offers new imaging possibilities of soft tissues. Among them breast is an ideal organ of interest, which is readily accessible, and there is still a need to improve the diagnostics and survival in one of the most frequent cancers worldwide. Unlike palpation, which is qualitative, elastography is capable of detecting smaller, deeper masses and providing quantitative information on their stiffness as characterized by elastic moduli. To estimate Young moduli the deformation is detected under stress. Elastography developed initially as a free-hand method (static elastography, strain elastography), where the stress was produced by the operator. It detects relative elastic properties, preventing precise quantification, and is highly operator-dependent. The newly developed shear wave elastography (SWE) eliminates the limitation of static elastography and raises hopes for wider application [4-7].

When interpreting elastograms, reference tissues such as glandular or fatty tissue are of importance. The stiffness of glandular tissue increases with age and minimally depends on the menstrual cycle. But, interestingly, we observed in our earlier study differences between inner and outer quadrants [4, 5]. The breast tissue proliferation is hormone dependent, but in our earlier study we did not observe a correlation between oestradiol levels and breast tissues stiffness. A moderate correlation was observed with the FSH/LH ratio (follicle stimulating hormone, luteinising hormone) [6]. Pregnancies, age of first delivery, body mass index or mastalgia seem not to influence breast elasticity as measured by shear wave elastography $[4,5]$.

The aim of our study was to evaluate the morphology of cystic breast lesions with special attention to quantification of Young moduli distribution. This initial analysis will also be the basis to discuss modification of breast lesion evaluation to increase the discriminating power of sonoelastography. 


\section{Material and methods}

Between January 2010 and February 2011 eighteen breast cystic lesions were evaluated in patients aged 26-55 (36.6 \pm 8.8$)$. Patients were qualified for fine needle biopsy. Conventional ultrasound with B-mode was performed on Aixplorer (Supersonic Imaging, France) with $15 \mathrm{MHz}$ probe. The volume of breast lesion was calculated from 3 dimensions, $V=0.523 \times A \times B \times C$. As the next step real-time sonoelastography with shear wave was performed. It consists of producing a deformation wave (oscillation) with frequency and power undetectable by the patient. This wave propagates transversally and tissue elastic properties are detected. The elastogram is a colour-coded map of tissue Young's moduli distribution. The method is described earlier in the literature [4-11]. The region of interest (ROI) was set to include the cystic lesion, and the area over and under the lesion, with sufficient lateral space (Fig. 1). The stiffness was measured in $\mathrm{KPa}$ in the lesions, at the margin, beneath the lesion and in reference glandular tissue. Mean, minimal, and maximal stiffness was estimated, and additionally the heterogeneity index was calculated as the percent value of the minimal to maximal range divided by the mean value. Because of partial propagation disappearance in cystic lesions, the area of propagation was calculated as the percent value. The analysis was performed as pixel calculation of the breast lesion and propagation area within the lesion in a histogram (Adobe Photoshop 7.0). Next fine needle biopsy with 22-25 gauge needles was performed and cytological examination performed. All lesions were definitely diagnosed as benign simple or complex cysts.

All data are presented as means \pm standard deviation (SD). Differences in parameters were analysed with the Mann-Whitney test after confirmation of non-normal distribution with the Kolmogorov-Smirnoff test. Correlations were analysed with Spearman's test. The SigmaStat 3.1 statistical software (Systat Software Inc) was used for analysis except for receiver operating characteristic curves, which were analysed with Medcalc 8.0 (Schoonjans, Belgium). The study was approved by local bioethics committee.

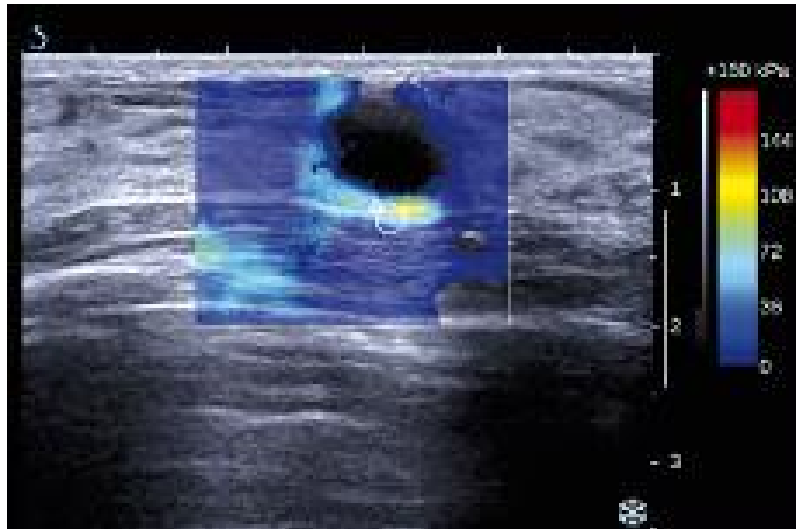

Fig. 1. Sonoelastographic scan of breast cyst with typical disappearance of propagation of shear wave

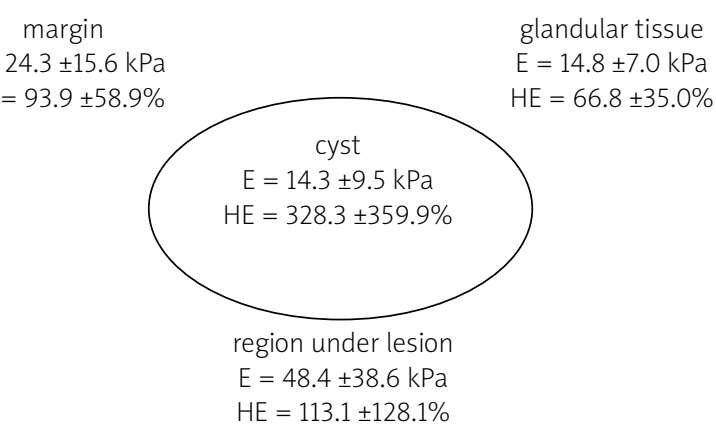

Fig. 2. Mean stiffness and heterogeneity in cystic lesion and surrounding tissues

\section{Results}

Mean volume of cystic lesions was $1295 \pm 2202 \mathrm{~mm}^{3}$ (30-7012). Mean stiffness and its heterogeneity in analysed area are presented in Fig. 2.

The difference between glandular tissue stiffness and cystic lesion residual stiffness was not statistically significant $(p=0.64)$. But comparing the cystic lesion with the

Table 1. Correlations of elastographic stiffness and B-mode sonography features

\begin{tabular}{|c|c|c|c|c|}
\hline Parameter & $\begin{array}{l}\text { Mean lesion } \\
\text { stiffness }(\mathrm{kPa})\end{array}$ & $\begin{array}{l}\text { Mean margin } \\
\text { stiffness }(\mathrm{kPa})\end{array}$ & $\begin{array}{c}\text { Mean glandular } \\
\text { tissue stiffness }(\mathrm{kPa})\end{array}$ & $\begin{array}{c}\text { Mean stiffness } \\
\text { under lesion }(\mathrm{kPa})\end{array}$ \\
\hline $\begin{array}{l}\text { Lesion volur } \\
\text { Rs } \\
p\end{array}$ & $\begin{array}{r}-0.49 \\
0.03\end{array}$ & $\begin{array}{r}-0.12 \\
0.63\end{array}$ & $\begin{array}{l}0.08 \\
0.73\end{array}$ & $\begin{array}{l}0.35 \\
0.14\end{array}$ \\
\hline $\begin{array}{l}\text { Propagation } \\
\text { wave in lesi } \\
\text { Rs } \\
p\end{array}$ & $\begin{array}{l}0.60 \\
0.009\end{array}$ & $\begin{array}{r}-0.18 \\
0.47\end{array}$ & $\begin{array}{r}-0.24 \\
0.32\end{array}$ & $\begin{array}{r}-0.51 \\
0.02\end{array}$ \\
\hline $\begin{array}{l}\text { Anechogeni } \\
\text { Rs } \\
p\end{array}$ & $\begin{array}{r}-0.18 \\
0.46\end{array}$ & $\begin{array}{r}-0.15 \\
0.53\end{array}$ & $\begin{array}{r}-0.33 \\
0.16\end{array}$ & $\begin{array}{r}-0.54 \\
0.02\end{array}$ \\
\hline $\begin{array}{l}\text { Hyperechog } \\
\text { lesion, later } \\
\text { Rs } \\
p\end{array}$ & $\begin{array}{r}-0.24 \\
0.32\end{array}$ & $\begin{array}{r}-0.18 \\
0.45\end{array}$ & $\begin{array}{r}-0.15 \\
0.52\end{array}$ & $\begin{array}{l}0.35 \\
0.14\end{array}$ \\
\hline
\end{tabular}


Table 2. Correlations of elastographic stiffness heterogeneity and B-mode sonography features

\begin{tabular}{|c|c|c|c|c|}
\hline Parameter & $\begin{array}{c}\text { Lesion stiffness } \\
\text { heterogeneity }(\mathrm{kPa})\end{array}$ & $\begin{array}{c}\text { Margin stiffness } \\
\text { heterogeneity }(\mathrm{kPa})\end{array}$ & $\begin{array}{c}\text { Glandular tissue } \\
\text { stiffness heterogeneity }(\mathrm{kPa})\end{array}$ & $\begin{array}{c}\text { Stiffness under lesion } \\
\text { heterogeneity }(\mathrm{kPa})\end{array}$ \\
\hline \multicolumn{5}{|c|}{ Lesion volume $\left(\mathrm{mm}^{3}\right)$} \\
\hline Rs & 0.36 & 0.44 & 0.18 & 0.42 \\
\hline$p$ & 0.14 & 0.06 & 0.46 & 0.07 \\
\hline \multicolumn{5}{|c|}{$\begin{array}{l}\text { Propagation of shear } \\
\text { wave in lesion (\%) }\end{array}$} \\
\hline Rs & -0.53 & -0.43 & -0.02 & -0.32 \\
\hline$p$ & 0.02 & 0.07 & 0.91 & 0.17 \\
\hline \multicolumn{5}{|c|}{ Anechogenic lesion } \\
\hline Rs & -0.13 & 0.02 & -0.15 & 0.30 \\
\hline$p$ & 0.60 & 0.91 & 0.53 & 0.20 \\
\hline \multicolumn{5}{|c|}{$\begin{array}{l}\text { Hyperechogenic area under } \\
\text { lesion, lateral shadows }\end{array}$} \\
\hline Rs & 0.18 & -0.01 & 0.24 & 0.15 \\
\hline$p$ & 0.45 & 0.95 & 0.32 & 0.52 \\
\hline
\end{tabular}

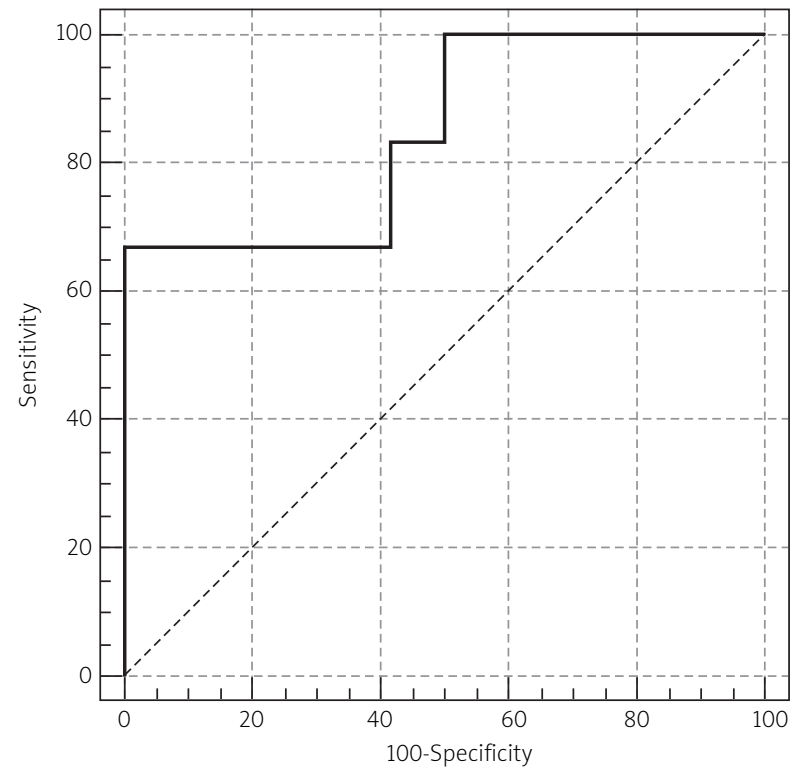

Fig. 3. The ROC curve in predicting disappearance of shear wave pro pagation in cysts over $400 \mathrm{~mm}^{3}$ volume

area under the cyst and margin the difference was statistically significant ( $p<0.001$ and $p=0.025$ respectively). The differences in stiffness heterogeneity between cyst and glandular tissue, margin and area under the cyst were significant ( $p<0.001 ; p=0.014 ; p=0.017$ respectively). We also analysed correlations between elastographic and B-mode sonography features; the results are presented in Tables 1 and 2.

The mean percentage of area within the lesion with detectable shear wave propagation was $61.6 \%$ (10-100\%). The percentage of detectable propagation within the lesion negatively correlated with lesion volume $(\mathrm{Rs}=-0.65$, $p=0.003$ ). The volume of lesion over $400 \mathrm{~mm}^{3}$ which corresponds with $9.15 \mathrm{~mm}$ diameter with sensitivity of $66.7 \%$ and specificity of $100 \%$ predicted $85 \%$ disappearance of propagation $(\mathrm{AROC}=0.85,95 \% \mathrm{Cl}: 0.61-0.96)$. The $\mathrm{ROC}$ curve is presented in Fig. 3.

\section{Discussion}

The typical elastographic distribution of stiffness in cystic lesions is described as BGR layering (blue/green/red). Depending on elastography equipment, colours coded as stiffness can differ. In our material the morphology of cystic lesion could be depicted as blue/propagation disappearance/yellow-red (Fig. 1). The 3-layer model also corresponds with quantitative measurements of Young's moduli $[12,13]$. Some elastographic morphological scoring systems have been proposed in the literature [14]. Thus we could propose a modification based on our results.

Benign lesions are characterized by a small difference between B-mode diameters and elastographic diameters (mean of $5 \%$ ). In malignant lesions this could increase to a mean difference of $50 \%$ and the stiff region is usually much larger than in B-mode. But Raza et al. evaluated lesions in an elastographic scoring system between 2 and 4 for some cystic lesions. But they used static elastography equipment [12]. We also evaluated stiffness of margins, and we omitted elastographic margins' thickness because they did not exceed $1 \mathrm{~mm}$. It added no information to our study, especially because the material was homogeneous. According to Barr et al., our lesions were all qualified as benign based on the elastographic to B-mode diameter ratio [15]. Furthermore, if we consider the diameter of the propagation "gap" (the area of no propagation within the lesion), the elastographic "gap" to B-mode diameter ratio would even more powerfully predict benign character. This could be an interesting proposal when modifying elastography scoring systems, but further research with comparative malignant and benign solid lesions is needed. The designed study is in progress. But in morphological analysis of cystic lesions a common denominator could be possible. Namely, Barr et al. depicted a typical breast cyst as a "bull's eye" in static elastography. The corresponding formula in our SWE consists of regions with similar shape: no propagation inside the cyst, elastic margins and a much stiffer region under the cyst [15]. Considering the reasons for similar scans, the mechanism of its origin is different. Typically the "bull's eye" is an artefact of liquid movement during free-hand compression. In shear wave elastography disappearance of prop- 
agation is a result of decorrelation and filtration in postprocessing $[16,17]$. In our material the mean area of propagation in cysts was $60 \%$. In a study performed by Athanasiou et al. in 7 cysts shear wave stiffness was evaluated as $0 \mathrm{kPa}$. It represents either absolutely no propagation or the authors did not measure residual detectable stiffness, despite use of equipment identical to ours [10]. But we also analysed small lesions, and propagation was usually present within cysts. In lesions over $9 \mathrm{~mm}$ we could predict almost no propagation ( $<15 \%)$ with satisfactory discriminating power. According to Tanter et al. in shear wave elastography propagation disappearance is observed and the authors present a few scans. Similarly to our observations, residual propagation is clearly detectable. Two reasons for this filtering can be proposed. First, the strong acoustic streaming induced in liquid areas can lead to a decorrelation of the successive ultrasonic data. Second, the strong modification of the shear displacement vs. the propagation direction yields to a decorrelation of shear displacement time profiles at neighbouring locations, resulting in a false time-of-flight estimation [17]. From a clinical point of view, it could be applied especially in complex and atypical cysts filled with liquid of higher echogenicity, without typical amplification under the lesion, etc, which are classified higher than BIRADS 2 (Breast Imaging Reporting and Data System) [17].

According to our results, besides elastography morphology evaluation, the advantage of SWE consists of additional propagation suppression in the lesion and residual stiffness similar to glandular tissue, higher stiffness under the cyst and higher heterogeneity of stiffness in the cyst. The observed promising quantitative results should be confirmed in clinical studies in differentiation between benign and malignant lesions $[12,18]$. The proposed analysis of elasticity heterogeneity seem to be an interesting option, especially because we observed in our previous study a strong correlation with insulin resistance, one of the known risk factors for breast cancer and a prognostic factor (unpublished data, in review). Evans et al. also observed similar results to ours of normal glandular and fat tissue heterogeneity, which is small. Tissues are more homogeneous regarding Young's moduli. But the authors did not make use of this fact in lesion differentiation [19]. In our previous study among 101 patients (808 elastographic scans) we observed similar heterogeneity of glandular and fat tissue (55.1 $\pm 18.0 \%$ and $61.4 \pm 24.4 \%$ respectively) [4].

Another important limitation of static elastography is the ability to differentiate lesions dependent on their localization. Deeper lesions (over $13 \mathrm{~mm}$ according to Raza et al. and over $20 \mathrm{~mm}$ according to Regini et al.) are less precisely diagnosed by elastography $[12,13]$. We did not observe among 18 cystic lesions problems with quality of elastograms. Sometimes the penetration option was used to fully visualize Young moduli in the whole scan.

To summarise, shear wave elastography offers a powerful tool for diagnosing benign breast cysts because of the highly specific morphology observed on elastograms. Further research with solid and malignant lesions and a larger group is needed.

\section{Conflict of interest}

None declared. The study was not sponsored by any funding body.

\section{References}

1. Zhi H, Ou B, Luo BM, Feng X, Wen YL, Yang HY. Comparison of ultrasound elastography, mammography and sonography in the diagnosis of solid breast lesions. J Ultrasound Med 2007; 26: 807-15.

2. Cho N, Moon WK, Park JS. Real-time US elastography in the differentiation of suspicious microcalcification on mammography. Eur Radiol 2009; 19: 1621-8.

3. Kumm TR, Szabunio MM. Elastography for the characterization of breast lesions: initial clinical experience. Cancer Control 2010; 17: 156-61.

4. Rzymski P. Skórzewska A, Skibińska-Zielińska M, Opala T. Factors influencing breast elasticity measured by the ultrasound Shear Wave elastography - preliminary results. Arch Med Sci 2011; 1, 127-33.

5. Rzymski P, Skórzewska A, Opala T. Changes in ultrasound shear wave elastography properties of normal breast during menstrual cycle. Clin Exp Obstet Gynecol 2011; 38: 137-42.

6. Rzymski P, Wilczak M, Opala T. Influence of sex hormones in women on breast elasticity measured by shearwave sonoelastography - a cross-sectional study. Gynecol Endocrinol. 2011 May 26. [Epub ahead of print].

7. Sammani A, Zubovits J, Plewes D. Elastic moduli of normal and pathological human breast tissues: an inversion-technique-based investigation of 169 samples. Phys Med Biol 2007; 52: 1565-76.

8. Sinkus R, Tanter M, Xydaes T, Catheline S, Bercoff J, Fink M. Viscoelastic shear properties of in vivo breast lesions measuered by MR elastography. Magnetic Res Imag 2005; 23: 159-65.

9. Tanter M, Bercoff J, Athanasiou A, Deffieux T, Gennisson JL, Montaldo G, Muller M, Tardivon A, Fink M. Quantitative assessment of breast lesion viscoelasticity: initial clinical results using supersonic shear imaging. Ultrasound Med Biol 2008; 9: 1373-86.

10. Athanasiou A, Tardivon A, Tanter M, Sigal-Zafrani B, Bercoff J, Defleux T, Gennisson JL, Fink M, Neuenschwander S. Breast lesions: quantitative elastography with supersonic shear imaging - preliminary results. Radiology 2010; 256: 297-303.

11. Evans A, Wheelehan P, Thomson K, McLean D, Brauer K, Purdie C, Jordan L, Baker L, Thomson A. Quantitative shear wave ultrasound elastography: initial experience in solid breast masses. Breast Cancer Res 2010; 104: 1-11.

12. Raza S, Odulate A, Ong EM, Chikarmane S, Harston CW. Using realtime tissue elastography for breast lesion evaluation: out initial experience. J Ultrasound Med 2010; 29: 551-63.

13. Regini E, Bagnera S, Tota D, Campanino P, Luparia A, Barisone F, Durando M, Mariscotti G, Gandini G. Role of sonoelastography in characterizing breast nodules. Preliminary experience with 120 lesions. Radiol Med 2010; 115: 551-62.

14. Rzymski P, Opala T. Elastografia jako nowe narzędzie wykrywania raka piersi - ocena badań i zastosowań klinicznych. Przegląd Menopauzalny 2011.

15. Barr RG. Real-time ultrasound elasticity of the breast: initial clinical results. Ultrasound Q 2010; 26: 61-6.

16. Garra BS, Cespedes El, Ophir J, Spratt SR, Zuurbier RA, Magnant CM, Pennanen MF. Elastography of breast lesions: initial clinical results. Radiology 1997; 202: 79-86.

17. Tanter M, Bercoff J, Athanasiou A, Deffieux T, Gennisson JL, Montaldo G, Muller M, Tardivon A, Fink M. Quantitative assessment of breast lesion viscoelasticity: initial clinical results using supersonic shear imaging. Ultrasound Med Biol 2008; 34: 1373-86.

18. Itoh A, Ueno E, Tohno E, Kamma H, Takahashi H, Shiina T, Yamakawa M, Matsumura T. Breast Disease: Clinical application of US elastography for diagnosis. Radiology 2006; 239: 341-350. 
19. Evans A, Wheelehan P, Thomson K, McLean D, Brauer K, Purdie C, Jordan L, Baker L, Thomson A. Quantitative shear wave ultrasound elastography: initial experience in solid breast masses. Breast Cancer Res 2010; 104: 1-11.

\section{Address for correspondence}

Paweł Rzymski MD PhD

Department of Mother's and Child's Health,

University of Medical Sciences Poznań,

Gynaecological and Obstetrical University Hospital,

Polna 33

60-535 Poznan

phone: +48 605393096

fax: +48 618419618

e-mail: parzymsk@gpsk.am.poznan.pl 